\title{
Study comparing the applicability of dorsal lumbotomy in older children
}

\author{
Jonathan Cloutier, MD; Nadim Haidar, MD; Marie-Pier Rompre-Deschenes, MD; Maryse Grimard; \\ Stéphane Bolduc, MD, FRCSC
}

See related article on page 440 .

Cite as: Can Urol Assoc J 2012;6:435-9. http://dx.doi.org/10.5489/cuaj.10064. Epub 2011 May 1.

\section{Abstract}

Objective: Dismembered pyeloplasty through dorsal lumbotomy to correct ureteropelvic junction obstruction is mainly successfully performed in children under 5 years old for technical reasons. We compared children who underwent dorsal lumbotomy by age group ( $<5$ vs. $\geq 5$ years old) to determine if the surgical success and long-term results were comparable.

Materials and Methods: We retrospectively reviewed the charts of 134 children undergoing a pyeloplasty. Group 1 consisted of children $<5$ years old $(\mathrm{n}=90)$ and Group 2 consisted of children $\geq 5$ years old. Patients' characteristics, as well as hospital stay, narcotic use, radiologic follow-up and success rate, were compared. Success was defined by absence of symptoms and $\geq 50 \%$ reduction in renal pelvis anteroposterior diameter and/or scintigraphic normalization of the drainage T1/2 when obtained. Univariate analysis was performed to compare the groups.

Results: Mean age (years) and weight $(\mathrm{kg})$ at surgery for Groups 1 and 2 were $1 / 8 \mathrm{~kg}$ and $11 / 35 \mathrm{~kg}$, respectively. Mean operative time was 98 minutes versus 120 minutes, respectively; mean hospital stay was 2.5 days for both groups and analgesia requirement was 50\% higher in Group 2. A Pippi-Salle stent was used in 90\% ( $n=120$ ) of cases. Mean follow-up was 26 months and the success rate was $89 \%$ and $90 \%$ for Groups 1 and 2, respectively.

Conclusion: Our study showed comparable success rates. We can infer that, as a technique, dismembered pyeloplasty is effective and safe in the younger and older children.

\section{Résumé}

Objectif : La pyéloplastie par démembrement par lombotomie dorsale pour les corrections de sténose de la jonction urétéropyélique est réalisée avec succès principalement chez les enfants de moins de 5 ans pour des raisons techniques. Nous avons comparé 134 enfants ayant subi une pyéloplastie par lombotomie dorsale en fonction de leur groupe d'âge ( $<5$ ans vs $\geq 5$ ans) afin de déterminer si la réussite chirurgicale et les résultats à long terme étaient comparables.

Matériel et méthodologie : Nous avons passé en revue de façon rétrospective les dossiers de 134 enfants ayant subi une pyéloplastie. Le groupe 1 comptait des enfants de $<5$ ans $(n=90)$ et le groupe 2 , des enfants de $\geq 5$ ans. Les caractéristiques des patients ainsi que la durée du séjour à l'hôpital, le recours à des narcotiques, le suivi radiologique et le taux d'efficacité de l'intervention ont été comparés. L'efficacité était définie comme l'absence de symptômes et une réduction de $\geq 50 \%$ du diamètre antéropostérieur du bassinet et/ou la normalisation du temps de vidange (T1/2) à la scintigraphie lorsque cette donnée était disponible. Une analyse univariée a été effectuée pour comparer les groupes.

Résultats : L'âge (ans) et le poids ( $\mathrm{kg}$ ) moyens au moment de I'intervention pour les groupes 1 et 2 étaient de 1 an et $8 \mathrm{~kg}$, et 11 ans et $35 \mathrm{~kg}$, respectivement. La durée opératoire moyenne était de 98 minutes et de 120 minutes, respectivement. La durée du séjour en hôpital était de 2,5 jours pour les deux groupes, et le besoin de recourir à des analgésiques était 50 \% plus élevé dans le groupe 2. Un cathéter de Pippi-Salle a été utilisé dans $90 \%$ ( $n=120)$ des cas. Le suivi médian a duré 26 mois, et le taux de réussite était de $89 \%$ et $90 \%$ dans les groupes 1 et 2, respectivement.

Conclusion : Notre étude a montré des taux d'efficacité comparables. Nous pouvons conclure que la pyéloplastie par démembrement est une technique efficace et sans danger chez les enfants, peu importe leur âge.

\section{Introduction}

Open dismembered pyeloplasty described by AndersonHynes is considered the gold standard to treat ureteropelvic junction obstruction (UPJO), with success rates exceeding $83 \%{ }^{1}$ Muscle-sparing incisions through dorsal lumbotomy provide adequate exposure for UPJO repair, while maintaining minimal convalescence time. Although pyeloplasty through dorsal lumbotomy is well-described in younger children ( $<5$ years old), experience in older children $(>5$ years old) remains limited due to presumed technical difficulties 
related to the procedure..$^{2,3,4}$ This technique was already applied in laparoscopy and extended to include the older group. Our objective is to study the feasibility and efficiency of open dismembered pyeloplasty through dorsal lumbotomy in children older than 5 years old and compare it to laparoscopy. However, it seemed interesting to first perform a retrospective study to demonstrate the applicability and the success of the open technique in the older group compared with the younger one, before embarking on the prospective study to compare the open and laparoscopic approaches.

\section{Materials and methods}

We retrospectively reviewed the charts of 134 consecutive patients undergoing primary and secondary repair of UPJO through a dorsal lumbotomy approach by a single pediatric urologist from September 2002 to September 2008. The study population was divided as follows: Group 1 included children $<5$ years old $(n=94)$ and Group 2 included older children $>5$ years old $(n=40)$.

The diagnosis of UPJO has been firmly established clinically and radiologically by an ultrasound and/or a MAG-3 Lasix renogram prior to surgery. A voiding cystogram was performed in all cases of neonatal hydronephrosis and in specific cases, if we suspected a vesicoureteral reflux. A peroperative retrograde pyelogram was performed if deemed necessary to confirm the diagnostic.

We recorded and compared patients' demographic data, including the age at the time of the surgery, sex, weight and body mass index (BMI). We categorized the types of presentation at diagnosis in both groups and classified them as follows: antenatal, flank pain, urinary tract infection, redo surgery and others. Our main follow-up imaging modality was the ultrasound, which was performed every 3 months for the first year, every 6 months the second year and then yearly afterwards. When the postoperative ultrasound did not demonstrate a significant improvement defined as $\geq 50 \%$ reduction of renal pelvis anteroposterior diameter, a MAG-3 lasix renogram was done.

We also compared the intra-operative and postoperative variables, including surgical time, the type of drain/ stent installed and its indwelling time. Other variables, such as peroperative or postoperative complications, analgesic requirements and length of hospitalization, were also studied. All patients were given prophylactic antibiotics until their drain was removed.

In the classical lumbotomy technique, the skin incision is vertical, but we used a subcostal transverse incision following Langer's lines of about $3.5 \mathrm{~cm}$ (Fig. 1). We dissected until we reached the dorsolumbar fascia, which was incised vertically down to the level of the iliac crest. After a vertical incision of the Gerota's fascia, a posterior dissection

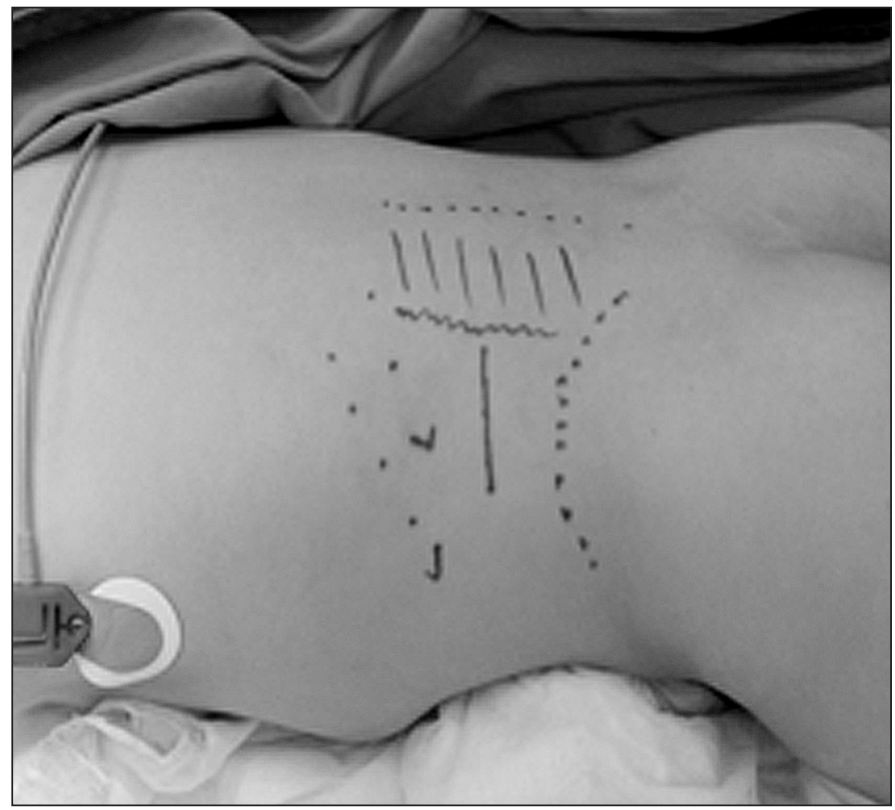

Fig. 1. Anatomic landmarks. Superiorly: 12th costal border. Inferiorly: Iliac crest. Medially: Paraspinal lateral muscle border.

was carried to the ureteropelvic junction. This approach has been found to be more aesthetic without compromising the adequacy of exposure.

Success was defined as symptomatic relief and objective ultrasound improvement in the anteroposterior renal pelvis diameter $(50 \%)$ or in the degree of hydronephrosis, as well as a scintigraphic normalization of the drainage half time (T1/2) when performed.

A dismembered pyeloplasty via lumbotomy was the only surgical approach considered in the study. All data were reported as a mean \pm standard deviation. Independent factors and success rates of the 2 groups were compared using the chi-square test ( $p<0.05$ was considered statistically significant). A univariate analysis was performed to analyse the other different variables.

\section{Results}

A total of 134 children underwent a dorsal lumbotomy approach for a UPJO. They were divided into 2 groups as described above. The mean age at surgery for each group ( 1 and 2 ) was $0.9 \pm 1.2$ year old and $10.7 \pm 3.7$ years old, respectively. In Group 1 ( $<5$ years old), the mean weight was $8 \pm 4.4 \mathrm{~kg}$ and $35.3 \pm 15 \mathrm{~kg}$ for Group 2 ( $>5$ years old). On the other hand, the BMI remained comparable between groups as there were no obese patients in our series. The BMI for each Groups 1 and 2 were $15.3 \pm 2.2$ and $17.5 \pm 3.0$, respectively (Table 1 ).

The most common presentation at diagnosis in Group 1 was antenatal hydronephrosis, which affected $78 \%$ of patients $(\mathrm{n}=73)$. For Group 2, it was flank pain, which 


\begin{tabular}{lcc}
\hline \multicolumn{3}{l}{ Table 1. Patients' characteristics } \\
\hline & $<\mathbf{5}$ years old & $\mathbf{2 5}$ years old \\
\hline No. patients & 94 & 40 \\
No. males/females & $63 / 31$ & $27 / 13$ \\
Mean age (yrs) & 0.9 & 10.7 \\
Mean weight (kg) & 8.0 & 35.3 \\
Mean BMI & 15.3 & 17.5 \\
No. left/right side & $62 / 32$ & $18 / 22$ \\
No. VUR/Total cystogram & $16 / 94$ & $0 / 4$ \\
No. intraoperative & $25(27 \%)$ & $17(43 \%)$ \\
pyelogram & & \\
Mean operative time (min) & 97.6 & 119.8 \\
Mean blood loss (cc) & 5.3 & 17.5 \\
\hline BMl: body mass index; VUR: vesicoureteral reflux.
\end{tabular}

affected $73 \%(n=29)$ (Table 2). Fourteen patients $(10 \%)$ in the study population had redo surgery; 8 patients were from the younger group and 6 were from the older group. Two-thirds of this older group were local patients and the others were referred from other centres.

A voiding cystourethrogram was performed in all patients in Group 1; subsequently, 16 of the 94 patients $(17 \%)$ were diagnosed with a vesicoureteral reflux (VUR). All of these patients with VUR had a MAG-3 lasix renogram with a Foley and intraoperative retrograde pyelogram to confirm the presence of UPJO.

The mean operative time was $97.6 \pm 28.5$ minutes and $119.8 \pm 21.6$ minutes for the younger and older group, respectively $(p<0.001)$. This difference was not explained by the higher number of intraoperative pyelogram done in the older group $(42 \%$ vs. $27 \%, p=0.32)$. However, when we analyzed the influence of the intraoperative retrograde pyelogram on the operative time in each group separately, it had a significant impact $(p<0.001)$. One hundred-twenty patients (90\%) in the study had a Pippi Salle catheter, 13 $(10 \%)$ had a double J catheter and only 1 patient had no catheter. The mean blood loss was $5.3 \pm 9.0 \mathrm{cc}$ for Group 1 and $17.5 \pm 12.5 \mathrm{cc}$ for Group 2. A polar vessel was identified in 1 patient (1\%) in Group 1 and 12 (30\%) in Group 2. No intraoperative complications were noted.

Postoperatively, in Group 1, problems with the Pippi Salle catheter were seen in 20 out of 83 patients (24\%), 4 of the 20 $(20 \%)$ had pyeloplasty failures and needed a redo surgery. In the older group, 8 out of $37(22 \%)$ had problems with the catheter and 1 patient consequently failed. Problems with the Pippi Salle catheter were defined as increasing pain upon closure of the catheter and relief when reopening and/or the presence of a urine leak around the stent.

The difference between the hospitalization time was not statistically significant $(p=0.9$ ) between the 2 groups ( 2.5 days). An epidural catheter was used in 8 children ( 5 in Group 1 and 3 in Group 2). The postoperative intravenous morphine requirement was higher in the Group 2 with $87 \%$

\begin{tabular}{lcc}
\hline Table 2. Initial presentation & & \\
\hline & $<5$ years old & $\geq 5$ years old \\
\hline Antenatal hydronephrosis & $73(78 \%)$ & $1(2 \%)$ \\
UTI & $7(7 \%)$ & $2(5 \%)$ \\
Flank pain & $1(1 \%)$ & $29(73 \%)$ \\
Hematuria & 0 & 0 \\
Redo surgery (failure) & $8(9 \%)$ & $6(15 \%)$ \\
Others & $5(5 \%)$ & $2(5 \%)$ \\
\hline UTI: urinary tract infection. & & \\
\hline
\end{tabular}

(35 patients) versus 36\% (34) in Group 1 ( $p<0.0001)$. Older patients were offered patient-controlled analgesia (PCA) (Table 3).

The mean follow-up was $26.2 \pm 12.2$ and $26.7 \pm 13.7$ months for Groups 1 and 2, respectively. In children under 5 years old, the mean change between the preoperative anteroposterior (AP) renal pelvis diameter and the last AP diameter on ultrasound postoperatively was $15.6 \pm 11.7 \mathrm{~mm}$; in this same group, we saw a mean preoperative and postoperative AP diameter of $29.0 \mathrm{~mm}$ and $13.5 \mathrm{~mm}$, respectively. In children over 5 , we found a mean change between the preoperative AP renal pelvis diameter and the last AP diameter on ultrasound postoperatively of $21.8 \pm 17.3 \mathrm{~mm}$; the mean preoperative and postoperative AP diameter was $36.4 \mathrm{~mm}$ and $15.8 \mathrm{~mm}$, respectively.

The success rate was $89 \%$ (84 out of 94 patients) for Group 1 and $90 \%$ (36 out of 40 patients) to Group 2. The difference was not statistically significant $(p=0.6)$. Postoperatively, only 1 patient from Group 1 developed an incisional hernia and needed a repair. No other complications were noted.

\section{Discussion}

Our study evaluated the feasibility and efficacy of open dorsal lumbotomy in older children. We presented 2 groups, with a total of 134 children with UPJO who were managed surgically by this technique. There is a scarcity of data in this age group since only Bajpai and colleagues, from India, reported a series of 36 patients in which they adopted a dorsal lumbotomy approach. ${ }^{1}$ Despite an abundance of literature regarding the open dismembered pyeloplasty in younger children, no studies have specifically compared the outcomes of this procedure in the older pediatric population ( $>5$ years old). A contributing factor is the dominance of laparoscopy. We think that our initial comparative study is essential to demonstrate the efficacy of this open technique in the older group before proceeding to our ultimate goal of comparing open dismembered pyeloplasty through dorsal lumbotomy to laparoscopic pyeloplasty in children $>5$ years old.

We found that $78 \%$ of the younger group presented with an antenatal hydronephrosis, which demonstrates the sensitivity and importance of the ultrasound in detecting this 
Cloutier et al.

\begin{tabular}{|c|c|c|c|}
\hline & $\begin{array}{l}<5 \text { years } \\
\text { old }\end{array}$ & $\begin{array}{l}\geq 5 \text { years } \\
\text { old }\end{array}$ & $p$ value \\
\hline Mean hospital stay \pm SD & $2.5 \pm 1.2$ & $2.5 \pm 0.6$ & 0.88 \\
\hline \multicolumn{4}{|l|}{ Analgesia } \\
\hline $\begin{array}{l}\text { Acetaminophen + } \\
\text { ibuprophen }\end{array}$ & $40(43 \%)$ & $2(5 \%)$ & \\
\hline $\begin{array}{l}\text { Acetaminophen }+ \\
\quad \text { ibuprophen }+ \text { codeine }\end{array}$ & $20(21 \%)$ & $3(8 \%)$ & $<0.0001$ \\
\hline $\begin{array}{l}\text { Acetaminophen }+ \\
\text { ibuprophen }+ \text { codeine }+ \\
\text { morphine and/or PCA }\end{array}$ & $34(36 \%)$ & 35 (87\%) & \\
\hline Mean follow-up (mos) & 26.2 & 26.7 & \\
\hline Success rate & $84 / 94(89 \%)$ & $36 / 40(90 \%)$ & 0.59 \\
\hline
\end{tabular}

pathology early and non-invasively. Therefore, it was used as our principal imaging modality for diagnosis and followup $(100 \%$ of our patients). The MAG-3 lasix was used postoperatively when the interpretation of the ultrasound was equivocal, and when recurrent UPJO needed to be ruled out. However, it had drawback due to its invasiveness and technical challenges in the pediatric population. Most of the studies show that renograms are only performed when there is persistent significant hydronephrosis. ${ }^{5-7}$

The operative time was longer in the older patient group; this is likely due to increased muscular mass, an exposed kidney and longer time in closing the wound in these older patients. It is difficult to compare our operative time with existing data because most of these studies include either a combined dorsal and subcostal approach or only subcostal one. Chacko and colleagues reported a mean operative time for minimally invasive flank approach of 132 minutes for patients $>5$ years old and 108 minutes for younger patients. ${ }^{8}$ These results are similar to our data, but with a different technique. Data from Bajpai and colleagues, who performed only dorsal lumbotomy, showed a mean operative time of 78 minutes with a mean age of 5 years old. However, the authors performed a larger incision compared to ours, which can explain the longer hospitalization and lower surgical time. $^{1}$

The analgesia requirement was higher in the older group. This may be related to a more extensive dissection needed for these patients. They also required increased tension on the tissue to create the working space. A recent study by Tanaka and colleagues indirectly corroborated our results for analgesia requirements. ${ }^{9}$ Chacko and colleagues reported that patients under 10 years old did not require narcotics during hospitalization. ${ }^{10}$

The hospitalization time was identical in both groups $(2.5$ days), which is comparable and even better than some of the published data with the open or laparoscopic approach. ${ }^{1,5,7,9}$ Some recent data showed similar hospitalization time in the open and the laparoscopic group, except with patients over 10 years old in the study by Tanaka and colleagues..$^{5,9}$

Ninety percent of patients in our study had a Pippi Salle catheter installed. This catheter is advantageous in its handling and cost effectiveness; a study by Braga and colleagues found a decrease of $\$ 565$ (CDN) per patient when they compared externalized pyeloureteral and standard stents and the preclusion of a second general anesthesia with the Salle catheter. ${ }^{11}$ No general anesthesia is required for its removal, so it could be done on an outpatient basis. In laparoscopy, often a double J stent is used, which requires general anesthesia. . $^{5-7,12}$

Even though we used a stringent criteria to define a successful outcome, our success rate was similar in both groups $(90 \%)$, which is comparable to the overall literature. ${ }^{1,5,8}$ It is understood that one cannot offer an open dorsal lumbotomy to all children over 5 and that our results in the older group are based on a mean BMI of 17.5 (which could be an influencing factor). However, it is important to keep in mind that the open dorsal lumbotomy is a viable approach to UPJO for children over 5 in a well-selected patient population.

The study limitations were principally its retrospective nature; this was our objective as we are planning a prospective study in the future. Our 2-year follow-up time may be considered short, yet we found that most recurrences came early in the primary pyeloplasty follow-up.

\section{Conclusion}

Open pyeloplasty by dorsal lumbotomy remains an interesting treatment for UPJO. For pediatric urologists who maintain their skills for this technique, the success and low complications rates, as well as the long-term results, are comparable to the other techniques. The dorsal lumbotomy in well-selected older children (heavy, but not obese children) is safe and provides good results as in younger patients. At this time, it would be interesting to perform a prospective study comparing laparoscopic and open pyeloplasty in older children, mainly to compare their cost-effectiveness.

Division of Urology, Centre Hospitalier Universitaire de Québec (CHUQ), Université Laval, Quebec, QC

Competing interests: None declared.

This paper has been peer-reviewed.

\section{References}

1. Baipai M, Kumar A, Tripathi $M$, et al. Dorsal lumbotomy incision in paediatric pyeloplasty. ANZ I Surg 2004;74:491-4.

2. Orland SM, Snyder HM, Ducket JW. The dorsal lumbotomy incision in paediatric urological surgery. J Urol 1987;138:963-6. 
3. Gonzalez R, Aliabadi H. Posterior lumbotomy approach in paediatric pyeloplasty. J Urol 1987; 137: 468-70

4. Kumar R, Smith G. Dorsal lumbotomy incision for paediatric pyeloplasty - a good alternative. Ped Surg Int 1999;15:562-4.

5. Piaggio LA, Franc-Guimond J, Noh PH et al. Transperitoneal laparoscopic pyeloplasty for primary repair of ureteropelvic junction obstruction in infants and children: Comparison with open surgery. I Urol 2007;178:1579-83.

6. Casale P, Grady RW, Joyner BD, et al. Comparison of dismembered and nondismembered laparoscopic pyeloplasty in the pediatric patient. J Endourol 2004;18:875-8.

7. Sukumar et al. Laparoscopic assisted dismembered pyeloplasty in children: intermediate results. Pediatr Surg Int 2008;24:403-6.

8. Chacko JK, Koyle MA, Mingin GC, et al. The minimally invasive open pyeloplasty. J Pediatr Urol 2006;2:368-72.
9. Tanaka ST, Grantham JA, Thomas JC, et al. A comparison of open vs laparoscopic pediatric pyeloplasty using the pediatric health Information system database-do benefits of laparoscopic approach recede at younger ages? J Urol 2008;181:1479-85.

10. Chacko JK, Koyle MA, Mingin GC, et al, Minimally invasive open renal surgery. J Urol 2007;178:1575-8.

11. Braga L, Lorenzo AJ, Farhat WA, et al. Outcome analysis and cost comparison between externalized pyeloureteral and standard stents in 470 consecutive open pyeloplasties. J Urol 2008; 180:1693-9.

12. Singh H, Ganpule A, Malhotra V, et al. Transperitoneal laparoscopic pyeloplasty in children. J Endourol 2007;21:1461-6.

Correspondence: Dr. Stéphane Bolduc, Division of Urology, Centre Hospitalier Universitaire de Québec (CHUQ), 2705, Boul Laurier, R-1742, Québec, QC GIV 4G2; fax: 418-654-2137; sbolduc_2002@yahoo.ca 